\title{
Time Management of the Clinical Nurses at Public Hospital in Bangladesh
}

\author{
Nibadita Barua1*, Meherun Nesa², Md. Abdul Latif ${ }^{2}$, Shariful Islam ${ }^{3}$ \\ ${ }^{1}$ Nursing Supervisor, Mugda Medical College Hospital, Dhaka, Bangladesh \\ ${ }^{2}$ Department of Nursing Management, NIANER, Dhaka, Bangladesh \\ ${ }^{3}$ Department of Adult and Elderly Nursing, NIANER, Dhaka, Bangladesh \\ Email: *nibaditab80@gmail.com
}

How to cite this paper: Barua, N., Nesa, M., Latif, Md.A. and Islam, S. (2019) Time Management of the Clinical Nurses at Public Hospital in Bangladesh. Open Journal of Nursing, 9, 1041-1053.

https://doi.org/10.4236/ojn.2019.910077

Received: July 27, 2019

Accepted: October 28, 2019

Published: October 31, 2019

Copyright (c) 2019 by author(s) and Scientific Research Publishing Inc. This work is licensed under the Creative Commons Attribution-NonCommercial International License (CC BY-NC 4.0). http://creativecommons.org/licenses/by-nc/4.0/

\begin{abstract}
Nursing is a very intense and focused career, so picking the right time and its proper management can help to relieve personal stress, manage tasks properly and achieve patients and organizational outcome. Objective: This study aimed to explore perceived time management skill of the clinical nurses. Methods: This was a descriptive correlational study design using simple random sampling. A total of 77 clinical nurses working in Mugda Medical College Hospital, Dhaka, Bangladesh were selected as study participants. The data were collected through structure questionnaire which consisted of demographic questionnaire and five dimensions of Time Management Skill Questionnaire (TMSQ). Results: The overall mean score of time management skill was $2.63(\mathrm{SD}=0.28)$ reflecting a medium level of nurses perceived time management skill. The results also revealed that nurses age $(r=0.39, \mathrm{p}=$ $0.000)$, monthly income $(r=0.294, p=0.017)$ and service experience $(r=$ $0.248, \mathrm{p}=0.030$ ) were statistically significant correlated with nurses' perceived time management skill. Conclusion: The outcome of this research would add to develop a strategy for nurse administrators to take an initiative for how nurses could improve the time management and utilize their limited time effectively. It specifies that proper time management can influence to provide quality care and achieving organizational goal.
\end{abstract}

\section{Keywords}

Time Management, Effective Time Management, Clinical Nurse, Hospital

\section{Introduction}

Time is one of the most valuable assets for everyone in everyday life, which is something that can be lost but cannot be found back. Effective time management 
is considered an important factor for a nurse manager to achieve the goals in an organization and accomplish the task on time; also it is a process of exercising the moral sense in performing a responsibility and control over the amount of time spent to accomplish a task and increase effectiveness, efficiency, and productivity [1].

In nursing, effective time management is always related to the quality of patient care, patient safety and job performance of a nurse in providing care [2]. Good time management raises the performance on individual and organization that is vital for a job holder to get the job done on time [3]. Effective time management is a condition for organizational productivity. Therefore, time management is essential for every organization to achieve its goals and objectives.

Though nursing is a popular and noble profession, but it combines with several challenges, especially in regards to availability of time for completing all tasks on time [4]. Undoubtedly, time management does not come naturally for many of us, it is an area of concern that needs special attention, a mechanism and continuous practice with personal behavior to achieve the goal and objectives [5] [6]. Consequently, in order to get effective time management may allow the following manner; skills in planning, setting priorities, delegating activities, organizing technique skills and minimizing time wasting are required elements for effective time management [4] [7].

Moreover, time management can be influenced by several factors, for example-1) internal factors such as; motivation and concentration, and 2) external factors included; high work load, improper planning of nurses, and poor organization of technique [8]. The result of ineffective time management is potentially serious for both nurses, their clients, colleagues, families, and the entire organization [9]. Consequently, poor time management may lead to employee's fatigue, stress, bad mood, loaf of work and may be exposed to illness.

According to World Health Organization [10] the global standard of nursepatient ratio in general is 1:15 [11]. In Bangladesh, although, there is a lack of exact statistics, but some studies reported that the existing nurse-patient ratio in most public hospitals is more than 1:80-100 in general which was more than 1 : 35 in 2005 [12]. Compared with the International Council of Nurses [13] nurse-patient ratios should be 1:1 in the Operating Room, 1:2 in the intensive care, critical care, and neonatal intensive care units, post-anesthesia recovery and labor and delivery, 1:4 in ante-partum post-partum, pediatric care, and in the emergency room and other specialty care units and 1:5 in general medical-surgical units. This means that nurses in Bangladesh need take care of almost double patients on the global standard which result a negative effect on the quality of a patient's care as well as on nurses' physical and emotional wellbeing. In order to manage this acute crisis, effective time management skills for nurses is utmost vital.

Moreover, the data showed that in government hospital, only $5.3 \%$ of a nurse's time was spent in direct contact with patient care, $32.4 \%$ for indirect patient care 
and, 50.1\% for paperwork [14]. In Bangladesh, recent pre-observational study findings show that $58 \%$ nurses were involved in direct patient care, $16 \%$ in indirect care, $18 \%$ eventful in unit related and $8 \%$ involved in personal activities [15]. This result shows nurses have not enough time to help other nurses while they are working.

Although, the effective time management is highly linked to the expected outcome of the quality of patient care; but in Bangladesh there is a lack of research evidence to address this issue in nursing. It is very usual that nurses in Bangladesh often claim for the shortage of time in relation to the workload that affecting the quality of nursing cares. But the researcher believes that along with several limitations, improper planning for time management in the clinical care is strongly influencing the quality of work performed by nurses and on the quality of patient care outcomes. Therefore, with that evaluation point of views, the researcher interested to examine nurses' perceived time management skill. The outcome of this research may contribute for nurse administrators to taking an initiative on how nurses could utilize their limited time effectively with high workload to maximize the quality of patient care, improve job performance, and quality of patient care outcome.

\section{Objectives}

1) General objective

To explore the clinical nurses' perceived time regarding time management skill.

2) Specific objectives

a) To describe socio-demographic characteristics of the clinical nurses;

b) To assess perceived time management skill.

3) To identify the relationship between demographic characteristics and time management skill of the clinical nurses.

\section{Methods}

This chapter describes the methodology used in this study, which included research study design, study participant, instrument, data collection method, and data analysis.

\subsection{Study Design}

A descriptive correlational design was done to explore perceived time management skills of the clinical nurses at a public hospital in Bangladesh from July 18 to June 19, 2019.

\subsection{Study Participant}

All clinical registered nurses were selected from the Mugda Medical College Hospital, Dhaka in Bangladesh. The subject was recruited by a simple random sampling technique. The total number of nurses in this hospital was about 229. The sample size was determined by $\mathrm{G}$ power analysis with an expected power of 
0.80 , estimated effect size of 0.30 and confidential interval $\mathrm{P}=0.05$. The calculated sample size was 64 . To reduce the attrition rate, $20 \%$ more sample was added. Therefore the total sample size of this study was 77. Researcher distributed a set of self-reported questionnaires among the participants. Nurses who had at least a diploma in nursing and midwifery degree or other equivalent educational qualification, clinically involved in direct patient care with 2 years' service experience in nursing and were willing to participate were included in the study.

\subsection{Instruments}

A total of 44 items questionnaire was used to collect the data from the participants. The questionnaire consisted of two parts. The questionnaire explains in detail below.

Part I: Socio-Demographic Data Related Questionnaire (SDDQ)

A 10 items socio-demographic data related questionnaire was used to measure the personal characteristics of nurses. The contents of the questionnaire included; age, gender, religion, educational status, service experience, monthly income, marital status, current working place, experience on current unit and any continuing education training on time management.

Part II: Nurses' Perceived Time Management Skills Questionnaire (NPTPMQ)

A 34 item previously validated Perception on Time Management Skills related questionnaire which was developed [16] was used to measure nurses' time management skills. The instrument was divided into 5 Dimensions including 1) Priorities, 2) Workload, 3) Delegation, 4) Schedule and 5) Technique. Each item was rated by using a 4 point Likert scale from $1=$ never practice to $4=$ always practice. This questionnaire is a modified version of the [17] developed to investigate the abilities of time management among top-level hospital administrators in Turkey.

Also, this instrument was modified by the researcher based on the time management questionnaire used by (19) items on the dimension of delegation and modified version of them on dimension of delegation (15) items to investigate the time management skill among clinical nurse in the context of Bangladesh. After modification the content was validated by three experts of NIANER. The internal consistency and reliability of the current study were yielded at the Cronbach'a alpha value of 0.81 , also the reliability was done upon 20 samples which were not included in the present study.

\subsection{Data Collection}

The proposal was approved by the Institutional Review Board (IRB) of NIANER Memo No-NIANER/General/2016/276 and BSMMU. After obtaining the permission for data collection, a letter from the director of NIANER was sent to the director of Mugda medical college hospital, Dhaka, Bangladesh. The data collection period was from December to January. Data collection permission was tak- 
en from Director of Mugda Medical College Hospital, Dhaka, Bangladesh (Permission Memo No: 500 beded/mgh/ad/2019 dated 12-1-2019). Then the researcher met with the nurses and briefly introduced them with the purpose of the study. The researcher had collected list of all RN from the Nursing superintendent's office and 77 nurses had been selected by lottery. The researcher communicated to the participants and explains the objectives of the study and invited them to participate in the study and asked their voluntary participation. Then researcher took a written informed consent from each participant who was willing to participate. The researcher also explained the nature of the study, invitation for participation in the study, and provides assurances about the anonymity, voluntary, and confidential nature of responses, methods for ensuring confidentiality and assuring that the participation was voluntary. After receiving the written consent forms, self-reported structured questionnaire had been delivered to the participant's hand to hand by the researcher. The participants asked to mark the section by using paper and pencil and return them directly to the researcher or to the in-charge nurse. A total of 77 participants returned the completed questionnaire to the researchers.

\subsection{Data Analysis}

Data were analyzed by using computer software (SPSS) version 23. Descriptive statistics including frequencies, percentage, mean, and standard deviation was used to describe the sample characteristics. Inferential statistics including Pearson Correlation test, t-test and ANOVA were used to test the relationship between socio-demographic characteristics and time management.

\section{Results}

This chapter summarizes the results of this study. The findings of the study described under the following headings including socio-demographic characteristics, nurses' perceived time management skill and the relationship between socio-demographic characteristics and time management skills.

\subsection{Socio-Demographic Characteristics}

Table 1 shows the frequencies, percentage, mean and SD of nurses related to socio-demographic characteristics. The finding shows that the mean age was $36.01 \pm$ 7.32 years, which was ranged from 25 - 54 years. Nearly half $(n=34,44.2 \%)$ of the participants were within the age of 35 - 44 years. Around $(n=70,90 \%)$ participants were female and $(n=58,75.3 \%)$ were religiously Muslim. The data revealed that monthly income was ranged from 16,000 - 56,000 taka with the monthly income mean was $35,181.25 \pm 8268.33$ taka. More than half $(\mathrm{n}=53$, $69 \%$ ) of the nurse participants were within the monthly income of $<35,000$. In terms of marital status, most of the participants $(\mathrm{n}=70,91 \%)$ were married. For education $(n=52,68 \%)$ participants had held a diploma in nursing degree, and the rest of them had held BSc or MSN degree. In this study, the participants were 
Table 1. Distribution of socio-demographic characteristics of the nurse participants $(\mathrm{N}=$ 77).

\begin{tabular}{|c|c|c|c|c|}
\hline Characteristics & Category & $\mathbf{n}$ & $\%$ & Mean \pm SD \\
\hline \multirow[t]{4}{*}{ Age (year) } & & & & $36.01 \pm 7.322$ \\
\hline & $25-34$ years & 32 & 41.6 & \\
\hline & $35-44$ years & 34 & 44.2 & \\
\hline & $45-54$ years & 11 & 14.3 & \\
\hline \multirow[t]{2}{*}{ Sex } & Male & 7 & 9.1 & \\
\hline & Female & 70 & 90.9 & \\
\hline \multirow[t]{2}{*}{ Religion } & Muslim & 58 & 75.3 & \\
\hline & Others & 19 & 24.7 & \\
\hline \multirow[t]{3}{*}{ Monthly income (Taka) } & & & & $35,181.25 \pm 8268.33$ \\
\hline & $<35,000$ & 53 & 68.8 & \\
\hline & $>35,000$ & 24 & 31.2 & \\
\hline \multirow[t]{2}{*}{ Marital status } & Married & 70 & 90.9 & \\
\hline & Single & 7 & 9.1 & \\
\hline \multirow[t]{3}{*}{ Educational status } & Diploma & 52 & 67.5 & \\
\hline & B.Sc. in nursing & 17 & 22.1 & \\
\hline & $\mathrm{MSc} / \mathrm{MPH}$ & 8 & 10.4 & \\
\hline \multirow[t]{5}{*}{ Current working place } & Medicine & 14 & 18.2 & \\
\hline & $\mathrm{ICU} / \mathrm{CCU}$ & 13 & 16.9 & \\
\hline & Pediatric & 8 & 10.4 & \\
\hline & Surgery & 29 & 37.7 & \\
\hline & Others & 13 & 16.9 & \\
\hline \multirow[t]{3}{*}{ Experience on current unit } & $<3$ months & 14 & 18.2 & \\
\hline & 3 - 9 months & 17 & 22.1 & \\
\hline & $>9$ months & 46 & 59.7 & \\
\hline \multirow[t]{3}{*}{ Service experience (year) } & $<8$ years & 49 & 63.6 & $8.02 \pm 6.80$ \\
\hline & $8-16$ years & 13 & 16.9 & \\
\hline & $>16$ years & 15 & 19.5 & \\
\hline Training on time management & Yes & 13 & 16.9 & \\
\hline
\end{tabular}

included from several departments such as medical (18.2\%), ICU/CCU (16.9\%), pediatric (10.4\%) surgery including; orthopedic and dialysis unit $37.7 \%$ and others $16.9 \%$. More than half $(59.7 \%)$ of the participants' length of working experience in a single unit was above 9 months. The overall mean service experience of the participants were $8.02 \pm 6.80$ years in which two third $(63.6 \%)$ of them had less than 8 years of service experience. Very few of nurses (16.9\%) received training on time management.

\subsection{Perceived Time Management Skill}

Perceived time management skill was measured using 34 items time manage- 
ment skill questionnaire with 4 points Likert scale. Table 2 shows the distribution and frequency, percentage, mean and SD of nurses on time management. The result revealed that the overall mean score of nurses was calculated as $2.63 \pm$ 0.28 out of 4 point, which indicates moderate level skill on the time management scale. The mean score for the dimension of workload related skill was $2.75 \pm$ 0.71 , delegation related skill was $2.62 \pm 0.4$, and schedule related skill were $2.34 \pm$ 0.56. Among five dimensions, nurses had more skill in priority related dimension mean was $3.23 \pm 0.89$ and fewer skills in technique related dimension mean was $2.03 \pm 0.54$. According to item analysis, majority of the nurses $(76.6 \%)$ always perform the main task and responsibilities. In terms of delegation related practice most of the nurses (79.2\%) always considered that task delegation is an important part for their job and majority of the nurses (77.9\%) perform their task by themselves than delegate other. However, larger number of nurses $(75.3 \%)$ usually found themselves compelled to return to work. Majority of the nurse (85.7\%) always delegate work correctly and expected exactly what to do. As regarded technique related practice, most of the nurses (76.6\%) thought that frequently meeting wasted more time and a huge percentage of nurse partcipants

Table 2. Distribution of nurses perception on time management skills $(\mathrm{N}=77)$.

\begin{tabular}{|c|c|c|c|c|c|c|c|c|c|c|}
\hline & \multirow[t]{2}{*}{ Items } & \multicolumn{2}{|c|}{ Never } & \multicolumn{2}{|c|}{ Very rarely } & \multicolumn{2}{|c|}{$\begin{array}{l}\text { Almost } \\
\text { always }\end{array}$} & \multicolumn{2}{|c|}{ Always } & \multirow[t]{2}{*}{$\mathrm{M} \pm \mathrm{SD}$} \\
\hline & & $\mathrm{n}$ & $\%$ & $\mathbf{n}$ & $\%$ & $\mathbf{n}$ & $(\%)$ & $\mathbf{N}$ & $(\%)$ & \\
\hline \multicolumn{10}{|c|}{ A. Priorities related practice } & $3.23 \pm 0.59$ \\
\hline 1 & Do the main tasks and responsibilities & 5 & 6.5 & 4 & 5.2 & 9 & 11.7 & 59 & 76.6 & $3.58 \pm 0.86$ \\
\hline 2 & Need time for each activity each day & 2 & 2.6 & 16 & 20.8 & 21 & 27.3 & 38 & 49.4 & $3.23 \pm 0.87$ \\
\hline 3 & Do the most important activity in my job & 5 & 6.5 & 9 & 11.7 & 16 & 20.8 & 47 & 61.0 & $3.36 \pm 0.93$ \\
\hline \multicolumn{10}{|c|}{ B. Workload related practice } & $2.75 \pm 0.71$ \\
\hline 7 & $\begin{array}{l}\text { Feel stressed or anxious about performing } \\
\text { tasks on time }\end{array}$ & 14 & 18.2 & 24 & 31.2 & 17 & 22.1 & 22 & 28.6 & $2.61 \pm 1.09$ \\
\hline 8 & Feel have more tasks than I can do & 3 & 3.9 & 30 & 39.0 & 28 & 36.4 & 16 & 20.8 & $2.74 \pm 0.83$ \\
\hline \multicolumn{10}{|c|}{ C. Delegation related practice } & $2.62 \pm 0.40$ \\
\hline 11 & Consider task delegation when make plans & 2 & 2.6 & 15 & 19.5 & 18 & 23.4 & 42 & 54.5 & $3.30 \pm 0.88$ \\
\hline 12 & $\begin{array}{l}\text { Consider task delegation is an important } \\
\text { part of my job }\end{array}$ & 5 & 6.5 & 3 & 3.9 & 8 & 10.4 & 61 & 79.2 & $3.62 \pm 0.84$ \\
\hline 13 & Perform tasks myself than delegate them & 1 & 1.3 & 2 & 2.6 & 14 & 18.2 & 60 & 77.9 & $3.73 \pm 0.58$ \\
\hline \multicolumn{10}{|c|}{ D. Schedule related practice } & $2.34 \pm 0.56$ \\
\hline 26 & Aware of time for extra tasks & 2 & 2.6 & 10 & 13.0 & 20 & 26.0 & 45 & 58.4 & $3.40 \pm 0.82$ \\
\hline 27 & $\begin{array}{l}\text { Feel unable to finish daily schedule tasks in } \\
\text { one day }\end{array}$ & 20 & 26.0 & 11 & 14.3 & 24 & 31.2 & 22 & 28.6 & $2.38 \pm 1.16$ \\
\hline \multicolumn{10}{|c|}{ E. Technique related practice } & $2.03 \pm 0.54$ \\
\hline 30 & Have lots of documents waiting to be read & 5 & 6.5 & 12 & 15.6 & 17 & 22.1 & 43 & 55.8 & $3.27 \pm 0.96$ \\
\hline 31 & Think meetings are a waste of time & 6 & 7.8 & 7 & 9.1 & 5 & 6.5 & 59 & 76.6 & $1.48 \pm 0.95$ \\
\hline 34 & Leave my tasks with uncompleted & 3 & 3.9 & 2 & 2.6 & 13 & 16.9 & 59 & 76.6 & $1.34 \pm 0.72$ \\
\hline \multicolumn{10}{|c|}{ Total mean score } & $2.63 \pm 0.28$ \\
\hline
\end{tabular}


(76.6\%) always left their tasks uncompleted and never give routine tasks to subordinate and non-routine task to them. The majority of nurses $(57.1 \%)$ reflected that, it was difficult for them to finish work-related conversation in time.

\subsection{Perceived time and Relationship Linking Total Time Management Skill and Each Dimension ( $=77)$}

Table 3 shows that the overall results of the all dimension of time management skill scale which indicate moderate levels of time management skill $2.63 \pm 0.28$ out of 4 point. The results showed that perceived time management skill of the clinical nurses for all dimensions at moderate level, except the dimension of priority mean score was at high level $3.2 \pm 0.5$, schedule and technique dimension had a low level of mean score $2.34 \pm 0.56 ; 2.03 \pm 0.54$ respectively.

\subsection{Relationship between Socio-Demographic Characteristics and Time Management Skills}

Table 4 reveals that the overall time management skill had significantly positive correlations with nurses age $(r=0.39, p=0.000)$, monthly income $(r=0.294$, $\mathrm{p}=0.015)$ and service experience $(\mathrm{r}=0.248, \mathrm{p}=0.030)$. However, gender $(\mathrm{t}=$ $-0.60, p=0.900)$, religion $(t=0.27, p=0.373)$, and experience on current unit $(\mathrm{r}=0.077, \mathrm{p}=0.508)$ were not significantly related with perceived time management skill.

\section{Discussion}

This study aimed to explore clinical nurses' perception regarding time management skill where 77 clinical nurses were involved in the study from Mugda Medical College Hospital, Dhaka, Bangladesh. This chapter describes the study finding based on the study results and objectives. The results are summarized under the following headings:

\subsection{Socio-Demographic Characteristics of the Nurses}

The result revealed that the mean age of nurses was 36 years. This finding was almost similar to the previous study in Iran and Pakistan conducted by [18] [19] respectively. Most of the nurses in this present study were Muslim (90\%).

Table 3. Nurse perceptions and relationship linking total time management and each dimension $(\mathrm{n}=77)$

\begin{tabular}{ccc}
\hline Dimension & Mean & SD \\
\hline Total time management & 2.63 & 0.28 \\
Priorities & 3.23 & 0.59 \\
Workload & 2.62 & 0.40 \\
Delegation & 2.62 & 0.40 \\
Schedule & 2.34 & 0.56 \\
Technique & 2.03 & 0.54 \\
\hline
\end{tabular}


Table 4. Relationship between socio-demographic characteristics and time management skill of the nurse participants $(\mathrm{N}=77)$.

\begin{tabular}{|c|c|c|c|c|}
\hline Variables & Category & Mean \pm SD & $\mathrm{F} / \mathrm{t} / \mathrm{r}$ & $\mathrm{P}$ \\
\hline \multirow[t]{3}{*}{ Age in years } & $25-34$ years $(a)$ & $2.54 \pm 0.22$ & 0.398 & 0.000 \\
\hline & $35-44$ years $(\mathrm{b})$ & $2.65 \pm 0.29$ & $c>b>a$ & \\
\hline & $45-54$ years $(c)$ & $2.81 \pm 0.27$ & & \\
\hline \multirow[t]{2}{*}{ Gender } & Male & $2.57 \pm 0.28$ & -0.60 & 0.90 \\
\hline & Female & $2.63 \pm 0.27$ & & \\
\hline \multirow[t]{2}{*}{ Religion } & Islam & $2.63 \pm 0.25$ & 0.27 & 0.37 \\
\hline & Others & $2.61 \pm 0.33$ & & \\
\hline \multirow[t]{2}{*}{ Monthly income (Taka) } & $<35,000$ & $2.57 \pm 0.24$ & .294 & .015 \\
\hline & $>35,000$ & $2.75 \pm 0.29$ & & \\
\hline \multirow[t]{2}{*}{ Marital status } & Married & $2.62 \pm 0.27$ & 0.93 & 0.34 \\
\hline & Single & $2.64 \pm 0.34$ & & \\
\hline \multirow[t]{3}{*}{ Educational status } & Diploma & $2.63 \pm 0.27$ & 0.34 & 0.79 \\
\hline & BSc in Nursing & $2.64 \pm 0.32$ & & \\
\hline & $\mathrm{MSC} / \mathrm{MPH}$ & $2.60 \pm 0.19$ & & \\
\hline \multirow[t]{5}{*}{ Current working place } & Medicine unit & $2.60 \pm 0.24$ & 1.078 & 0.364 \\
\hline & $\mathrm{ICU} / \mathrm{CCU}$ & $2.74 \pm 0.41$ & & \\
\hline & Pediatric unit & $2.65 \pm 0.134$ & & \\
\hline & Surgery unit & $2.65 \pm 0.13$ & & \\
\hline & Other & $2.71 \pm 0.19$ & & \\
\hline \multirow[t]{3}{*}{ Experience on current unit } & $<3$ months & $2.57 \pm 0.251$ & 0.077 & 0.508 \\
\hline & $3-9$ & $2.64 \pm 0.25$ & & . \\
\hline & $>9$ months & $2.64 \pm 0.29$ & & \\
\hline \multirow[t]{3}{*}{ Service experience } & $<8$ years $(\mathrm{a})$ & $2.59 \pm 0.25$ & 0.248 & 0.030 \\
\hline & $8-16$ years $(b)$ & $2.57 \pm 0.25$ & $c>a>b$ & \\
\hline & $>16$ years $(\mathrm{c})$ & $2.78 \pm 0.33$ & & \\
\hline \multirow[t]{2}{*}{$\begin{array}{l}\text { Training on time } \\
\text { management }\end{array}$} & Yes & $2.67 \pm 0.28$ & 0.20 & 0.65 \\
\hline & No & $2.62 \pm 0.27$ & 0.20 & 0.65 \\
\hline
\end{tabular}

It might be due to Bangladesh is an Islamic State. Whether, very few nurses (9.1\%) were male while most of the nurses were female (90\%) in the current study it might be due to nursing is a female-oriented profession like other countries. In terms of marital status, most of the nurses (90.9\%) were married, which was similar to another study conducted by [20] in Iran. It was found that for education, $67.5 \%$ nurse had a diploma, (22\%) nurse had BSc degree, and the rest of them having MSN degree. The highest number of diploma nursing may be due to less opportunity for nurses to receive higher education in the country. Until 2006, Bangladesh had only one BSc nursing college. This result is consistent with previous study conducted by [21] in Egypt. 


\subsection{Perceived Time Management Skill}

Present study results revealed that the overall mean score on perceived time management skills of nurses was moderate. It might be due to poor staffing, inappropriate assigning tasks, lack of knowledge about technology use, and improper scheduling. The result of this study is consistent with the previous study conducted by [22].

In this study, the time management skill of the nurses was measured for 5 dimensions scales. Among them, a dimension of priorities of time management was found to be the highest mean score of $3.23(\mathrm{SD}=0.59)$. The possible explanation is may be due to carefully consider the patient activity based on the prioritization system. Therefore, this result proved that nurses perform their tasks based on the prioritization system. Also, this result was supported by [9] who stated that it might be due to nurses' ensured safety for the patient being responsible for prioritization system. Similarly, [18] in Iran, they mentioned nursing profession is critical and it is evident that nurses are always working based on prioritization system. Conversely, another study in Egypt showed the mean score of "Periodization skill" was at moderate level due to being interrupted by telephone conversations, and difficulties to finish work-related conversations [9].

On the other hand the lower perceived skill in time management for the dimension of "Technique" was at low level. It means that nurses have lack of individualized competency in organizing work. The Nurses had a low level of technique in time management because they did not have theoretical knowledge rather they had more practical experience regarding technique. Nurses need to have more theoretical knowledge to improve their technique to manage the time effectively. A similar result was found in another study by [23] where Researcher stated that it might be due to not being able to finish conversations in the right time, being constantly interrupted by telephone calls, that's why not being able to accomplish tasks in a timely manner.

\subsection{Relationship between Socio-Demographic Characteristics and Time Management Skill}

The findings of the present study indicated that time management skill had a significant positive relationship with nurses' age. It means that Nurses who had higher the age higher the perceived time management skill. It means that when someone is going to be old, he or she becomes more responsible. A similar study found in Egypt and Iran conducted by [18] respectively. They mentioned that time management in various age groups was significantly different. This study also indicated that increased age had the highest level of time management skills. It might be due to increased responsibility with increased age. The result of this study shows that, Medicine unit, ICU/CCU, Pediatric unit, Surgery unit and Other; including Nephrology, Gestroentology nurses time management almost same. This result might be due to majority of nurses $(n=52,68 \%)$ had completed diploma in nursing education under same curriculum and very few nurses 
who got training on time management. A positive significant association between time management and service experience was found. Nurses who had more service experience had higher levels of time management skills. It means that nurses who were more exposed to work they developed more experience. Therefore, this relation between time management skill and service experience might be due to the length of service experience, education and training. However, in the current study education and training is not significant with the time management skill. This result is similar to another study conducted by [18] [23] in Iran. They mentioned experience in various age groups was significantly different in time management. It might be due to increasing nurses' experience in verities setting and environment enhances their responsibility by handling real situation.

\section{Conclusion}

On the whole, senior nurse managers enjoyed a favorable status regarding time management skills and behaviors. Comparison of the mean scores of time management skills indicated a significant difference in age, monthly income, service experience, and perceived time management skill. Findings suggest that proper time management can influence to provide quality care and achieving organizational goal. The nurse manager or administrator may able to identify the nurse's practice on time management and thereby can initiate to improve.

\subsection{Limitation}

Several limitations to this study were identified. Firstly, study participants were not enough for random sampling. Secondly, due to limited study, it was difficult to compare. Finally the majority of the participants were female, therefore the difference between male nurses and female nurse's time management was not actually found.

\subsection{Recommendation}

1) The recommendations for further studies will base on the results of this study.

2) Time management training programs must be provided for nursing staff to improve current use policies, rules, and regulations should be clear for staff to save time of time management perception toward effective organizational performance and decrease time wasters.

3) Meetings should be carefully organized through determining in advance purposes, time, place, and attendances which help in saving time.

4) Replicate this study in other different types of hospitals in Bangladesh.

\section{Conflicts of Interest}

The authors declare no conflicts of interest regarding the publication of this paper. 


\section{References}

[1] Ahmad, N.L., Yusuf, A.N.M., Shobri, N.D.M. and Wahab, S. (2012) The Relationship between Time Management and Job Performance in Event Management. Social and Behavioral Sciences, 65, 937-941. https://doi.org/10.1016/j.sbspro.2012.11.223

[2] Tzeng, H.M. and Ketefian, S. (2003) Demand for Nursing Competencies: An Exploratory Study in Taiwan's Hospital System. Journal of Clinical Nursing, 12, 509-518. https://doi.org/10.1046/j.1365-2702.2003.00738.x https://pdfs.semanticscholar.org/ebeb/b3e25ba00430198a29972978c8421489a6b0.pd f

[3] Pearce, C. (2007) Ten Steps to Managing Time: Chris Pearce Offers a Guide to Help Nursing Leaders Manage Time Effectively. Nursing Management, 14, 23. https://doi.org/10.7748/nm2007.04.14.1.23.c4340

[4] Qteat, M.M. and Sayej, S. (2014) Factors Affecting Time Management and Nurses' Performance in Hebron Hospitals. Journal of Education and Practice, 5, 41-58. http://file:///C:/Users/ASUS/Downloads/17453-19715-1-PB.pdf

[5] Claessens, B.J. (2004) Perceived Control of Time: Time Management and Personal Effectiveness at Work. Technische Universities Eindhoven, Eindhoven.

[6] Steven, S. (2009) 13 Principles of Effective Time Management for Freelancer. http://www.designm.ag/freelance/principles .tim./principles .tim

[7] Gordon, C.E. and Borkan, S.C. (2014) Recapturing Time: A Practical Approach to Time Management for Physicians. Postgraduate Medical Journal, 90, 267-272. https://doi.org/10.1136/postgradmedj-2013-132012

[8] Hee, O.C. and Kamaludin, N.H.B. (2016) Motivation and Job Performance among Nurses in the Private Hospitals in Malaysia. International Journal of Caring Sciences, 9, 342-347. http://www.international.journalofcaringsciences.org/docs/33Hee_special_9_1.pdf

[9] Ahmed, M. Z. (2012) Time Management Challenges among Jordanian Nurse Managers. Life Science Journal, 9, 2464-2469. http://www.lifesciencesite.com

[10] WHO (2007) Country Cooperation Strategy. http://www.searo.who.Int/en/Section1430/section1433/section1618

[11] Fardaus, A. (2008) Key Issues to Health Governance in Bangladesh. Paper Presented at the 2nd International Conference on Challenges of Governance in South Asia, Kanthmandu, Nepal.

[12] Latif, A., Nahar, L., Khatun, S., Akter, B., Akhter, N., Khatun, S. and Begum, T. (2011) In-Depth Country Assessment on Nursing and Midwifery in Bangladesh. http://file:///F:/4th\%20Semister/4th\%20Semister(Final)/My\%20theses/Final\%20Def ence/Time/Time/In-depth_Country_Assessment.pdf

[13] International Council of Nurses (2009) https://www.google.com

[14] Akter, B. (2010) Transformational Leadership of Nurse Supervisor Expected and Perceived by Nurse in Bangladesh. Prience of Songkla University, Thailand's Southern Region.

[15] Baroi, F., Sahajahan, M., Sultana, P., Faruque, M.H. and Yasmin, N. (2017) Activity analysis of Nurses working in a Teaching Hospital Dhaka, Bangladesh. Journal of Medical and Biological Science, 3, 14-18.

[16] Kisa, A. and Ersoy, K. (2005) The Need for Time Management Training Is Universal: Evidence from Turkey. Hospital Topics, 83, 13-19.

[17] Erdem, R. (1997) Time Management and an Experimental Investigation on Top 
Managers of Hospitals. In: Kisa, A. and Ersoy, K. Eds., The Need for Time Management Training Is Universal: Evidence from Turkey, 13-19.

[18] Ziapour, A., Khatony, A., Jafari, F. and Kianipour, N. (2015) Evaluation of Time Management Behaviors and Its Related Factors in the Senior Nurse Managers, Kermanshah-Iran. Global Journal of Health Science, 7, 366-337. https://doi.org/10.5539/gjhs.v7n2p366

[19] Habib, A., Afzal, M., Hussain, M., Naseer, A., Habib, T. and Gilani, S.A. (2018) Factors Effecting Time Management of Professional Nurses' at Public Hospital, Lahore. International Journal of Social Sciences and Management, 5, 231-235. https://doi.org/10.3126/ijssm.v5i3.20606

[20] Ebrahimi, H., Hosseinzadeh, R., Tefreshi, M.Z. and Hosseinzadeh, S. (2014) Time management Behaviors of Head Nurses and Staff Nurses Employed in Tehran Social Security Hospitals, Iran in 2011. Iranian Journal of Nursing and Midwifery Research, 19, 193.

[21] El-Shaer, A.M. (2015) Impact of Time Management Program on Time Wasters of Head Nurses and Their Perception toward Effective Organizational Performance. Journal of Nursing and Health Science, 4, 18-30.

[22] Aduke, A.F. and Immaculata, O. (2012) Influence of Time Management on Administrative Effectiveness in Higher Institutions in Ekiti State. International Journal of Educational Research and Technology, 3, 61-65.

[23] Zakaria, A.M. (2016) Effectiveness of Learning Module on Time Management Ability and Delegation Skills for Head Nurses. IOSR Journal of Nursing and Health Science, 5, 31-40. 